\title{
The Location and Accessibility of the Second Mesiobuccal Canal in Maxillary First Molar
}

\author{
Aysun Kara Tuncera \\ Faruk Haznedaroglu ${ }^{b}$ \\ Semih Sert ${ }^{c}$
}

\section{ABSTRACT}

Objectives: The purpose of this study was to examine the location and accessibility of the second mesibuccal canal in maxillary first molar of a Turkish sub-population.

Methods: Presence and accessibility of the MB2 canal in 110 extracted maxillary first molars was examined with unaided vision, dental loups and the DOM. To characterize the geometrical location of MB2 canals, photographs of pulp chambers were obtained.

Results: With the unaided vision, 58 MB2 canal orifices and after evaluation with the dental loup, DOM an additional 28 MB2 canal orifices were detected. In 65 molars, the MB2 canal orifices was located $0.87 \mathrm{~mm}$ distally and $1.73 \mathrm{~mm}$ palatally to the main mesiobuccal canal and in the remaining 21 molars was $0.72 \mathrm{~mm}$ mesially and $1.86 \mathrm{~mm}$ palatally.

Conclusions: Presence of second mesiobuccal canal was similar to the other studies but in a Turkish sub-population it originates mainly distal to the main MB canal. (Eur J Dent 2010;4:12-16)

Key words: Second mesiobuccal canal; Maxillary molar; Location; Accessibility.

- a Department of Endodontics, Faculty of Dentistry, Istanbul University, Istanbul, Turkey.

b Professor, Department of Endodontics, Faculty of Dentistry, Istanbul University, Istanbul, Turkey.

Assistant Professor, Department of Dental, Derince Military Hospital, Izmit, Turkey.

- Corresponding author: Aysun Kara Tuncer, Department of Endodontics, Faculty of Dentistry, Istanbul University, Capa, Istanbul, Turkey.

Phone: +90 2124142020 +905335705060

E-mail: aysunkara80』gmail.com

\section{INTRODUCTION}

The aim of root canal treatment is meticulous cleaning, shaping and filling of the root canal system. A prerequisite for successful root canal treatment is the preparation of an adequate access cavity, location and identification of the root canal orificies. In order to achieve this it is important that the clinician has a detailed knowledge of the root canal morphology. Initially, Hess and Zurcher ${ }^{1}$ noted the complexity of the mesiobuc- 
cal roots of first and second maxilllary molars. After the study of Weine et al, ${ }^{2}$ many similar studies were performed using different methods to assess canal morphology. ${ }^{3-7}$ The differences between these studies may be due to the examination of teeth in vivo or in vitro, using of dental loups or operating microscopes for location of the MB2 canal, radiographic examination or canal staining and root clearing method for identification of root canal system. Another reason of discrepancy between these findings may be related to racial origin of tooth sources. Previous studies have been mainly performed on teeth of American, Canadian and Japanese populations. ${ }^{2,4,8-13}$ Wasti et al ${ }^{14}$ found the prevalence of the MB2 canal in maxillary first molars of South Asian Pakistan 53.3\% whilst Ng et $\mathrm{al}^{15}$ reported $67.8 \%$ of Burmese maxillary molars.

It is important to know for successful endodontic therapy that the root canal morphology exhibit variations related to the racial origin. The purpose of this study was to examine the location and accessibility of the second mesiobuccal canal in maxillary first molars.

\section{MATERIALS AND METHODS}

One hundred ten extracted maxillary first molars were collected from general dental clinics within Istanbul,Turkey. All of the teeth that demonstrated fully formed roots were identified at the time of extraction as maxillary first molars. In addition, the teeth were verified as maxillary first molars by anatomical characteristics and stored in $1 \%$ thymol solution. After the cleaning of the teeth of any adherent soft tissues, bone fragments and calculus by scaling, a size 6 round bur in a low speed handpiece with water spray was used to remove the dental caries and the top of the pulp chamber. After the location of the main mesiobuccal canal, the accessibility was examined. If no accessibility to the apex was possible, the tooth was discarded thus physiologically and pathologically uncalcified teeth were used in this study. The teeth were placed in $2.5 \%$ sodium hypochlorite for $24 \mathrm{~h}$ and washed under running tap water for $4 \mathrm{~h}$, then dried at room temperature for $24 \mathrm{~h}$. All the external root surfaces were covered with three coats of nail varnish in order to prevent embedding material from entering the root canal system. Each teeth was embedded in clear resin and decoronated at the cementoenamel junction using a low-speed saw (Isomet Buehler Ltd., Lake. Bluff, IL, USA) under water irrigation.

The pulp chamber floor was evaluated and the remaining organic tissues was removed mechanically using dental explorer. After the location of the canal orifices, the teeth were submerged again in high volume of $2.5 \%$ sodium hypochlorite for $24 \mathrm{~h}$ and then washed under running tap water for $4 \mathrm{~h}$ before placement in an ultrasonic bath.

The following observations were made as clinical 1) presence of second mesiobuccal canal 2) accessibility 3) root canal configuration using Vertucci's classification' 4) geometrical location.

Presence of the MB2 canal orifice was firstly examined with unaided vision. If the second mesiobuccal canal was located, size $0.6,0.8$ or $10 \mathrm{~K}$ type files was used with Glyde (Dentsply Maillefer) as the lubricant to determine the accessibility. The accessibility procedure was described in relation to access to either: coronal, middle or apical thirds. If an orifice was located but a file was unable to reach the apical third, the root canal was evaluated inaccessible.

If an orifice was located but size $0.6,0.8$ or 10 K-type files was unable to penetrate into the canal, no bur was used to remove dentine on the pulp chamber floor. If a second mesiobuccal canal orifice was not located with unaided vision, the teeth then evaluated using dental loups. After the determination of the presence of the MB2 canal the accessibility was performed using size $0.6,0.8$ or $10 \mathrm{~K}$-type files with Glyde (Dentsply Maillefer). Finally the teeth with unlocated MB2 canal orifices were examined by using the DOM at x25.0 magnification and a MB2 canal orifice was either located or not located (Figure 1).

To categorize the canal system in MBR (mesiobuccal root) mesio-distal and bucco-palatal radiographs were obtained. The size 0.8 files were placed into the main mesiobuccal and second mesiobuccal canal. The teeth with no access to the apex were eliminated. Before photographing of pulp chambers millimetric glass scale was placed in order to make measurements to characterize the geometrical location of MB2 canals. The main mesiobuccal, palatal and MB2 canal orifices were marked on the millimetric glass scale. The main mesiobuccal canal and the palatal orifices were connected through a line MB-P and in addition to this line a perpendicular line was drawn from the 
MB2 canal orifice to the M-P line. The main mesiobuccal canal was accepted as the origin and the vertical distance from MB2 to MB-P line was measured, as described by Görduysus et al $^{16}$ (Figure 2). The images were analyzed by Image-Proplus 4.0 software to measure the relationship between MB2 canal and other canals.

\section{RESULTS}

The second mesiobuccal canal was found in $78 \%$ of the 110 maxillary molars and in 17 (19.8\%) of these MB2 canals it was accessible to the apex. The teeth with no access to the apex were dis-

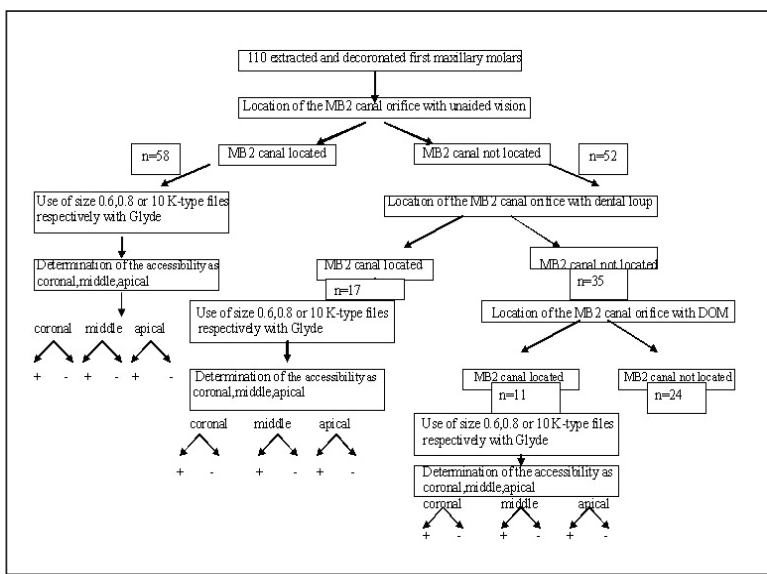

Figure 1. Clinical appearance of the same lesion. The overlying mucosa was normal and there was not any sign or symptom.

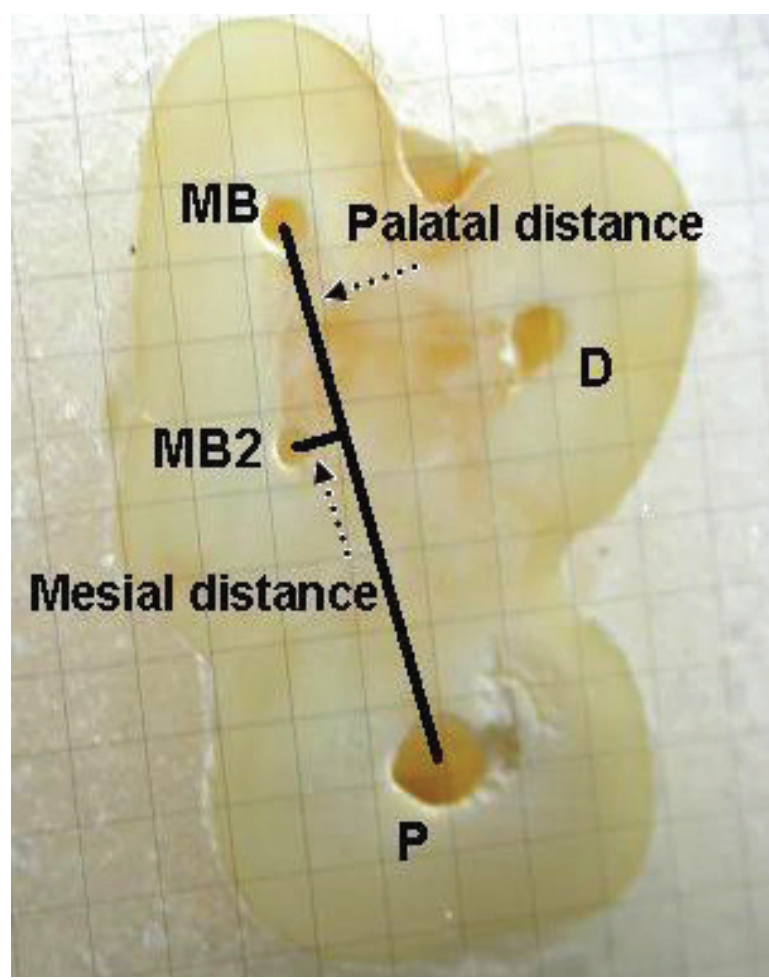

Figure 2. On the millimetric glass scale, measurements were made to characterize the geometrical location of MB2 canals. MB: mesiobuccal canal orifice, MB2: second mesiobuccal canal orifice, $P$ : palatal canal orifice. carded and of the remaining 17, $3(17.6 \%)$ had a Vertucci Type IV and 14 (82.4\%) were Vertucci Type Il canal system.

With the unaided vision 58 MB2 canal orifices and after evaluation with the dental loup an additional 17 MB2 canal orifices were detected. $68 \%$ of MB2 canals were located by using methods and 11 additional MB2 canals were identified with the use of the DOM (Figure 1). In 65 (75.6\%) molars the MB2 canal orifices was located $0.87 \mathrm{~mm}$ distally and $1.73 \mathrm{~mm}$ palatally to the main mesiobuccal canal and in the remaining $21(24.4 \%)$ molars was $0.72 \mathrm{~mm}$ mesially and $1.86 \mathrm{~mm}$ palatally as represented in the Figure 3.

\section{DISCUSSION}

In the present study it was found that $78.18 \%$ of maxillary first molar possessed a second mesiobuccal canal. This is consistent with the findings of Burhley et $\mathrm{al}^{17}$ but higher than that reported by Sempira and Hartwell. ${ }^{6}$ In the study of Sempira and Hartwell ${ }^{6}$ the second mesiobuccal canal had to be negotiated and obturated either separate from MB or within $4 \mathrm{~mm}$ of the apex. If two separate orifices blended into a single canal coronally during instrumentation, it was not considered to be a separate canal. This criteria is probably one of the reasons for the lower incidence of second mesiobuccal canals.

Burhley et $\mathrm{al}^{17}$ found that the frequency of MB2 canal detection for the microscope, dental loupes and no magnification groups was $71.1 \%, 62.5 \%$ and $17.2 \%$, respectively. Baldassari-Cruz et al ${ }^{18}$ reported that the percentage of second mesiobuc-

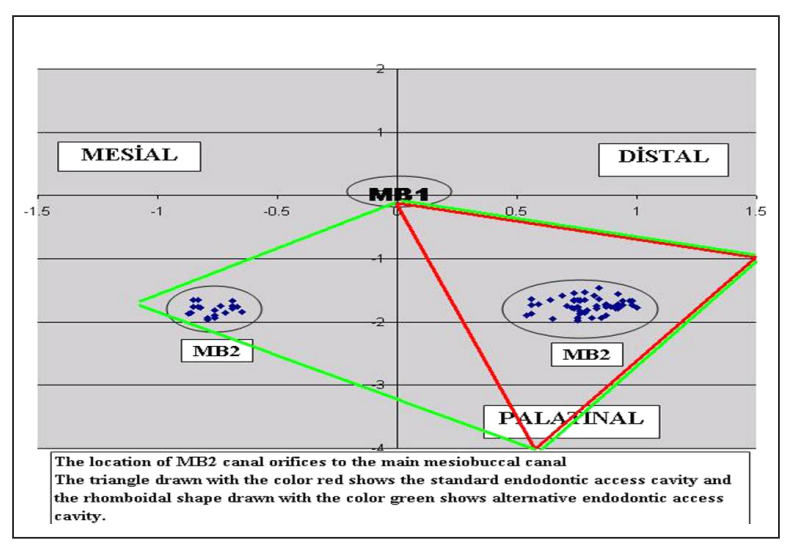

Figure 3. The location of MB2 canal orifices to the main mesiobuccal canal. The triangle drawn with the red color shows the standard endodontic access cavity and the rhomboidal shape drawn with the green color shows alternative endodontic access cavity. 
cal canals was $82 \%$. All these studies were performed using magnification. The effectiveness of using a surgical/dental operating microscope for detection of MB2 has been evaluated. ${ }^{16-21}$ The result of these studies demonstrated that the magnification of the operating field increased a MB2 canal detection rate. The two-canalled mesiobuccal roots of Turkish maxillary first molars in this study frequently exhibited Vertucci type II (82\%) and IV $(17 \%)$ canal configuration. The results of the present study were similar to that in Japanese sub-population. ${ }^{4}$ Both in this studies it was used radiographic techniques by determining the canal configuration of the two-canalled mesiobuccal roots. In contrast to our study type IV configurations were found in a large percentage by the other studies., 14,15 The differences may be owing to method of canal identification. The method of canal staining and root cleaning may show the complexities of root canal anatomy compared to conventional radiographies because a radiographic image is a two-dimensional representation for a three-dimensional object. ${ }^{21}$ In the present study the aim was to determine the root canal system clinically thus we did not use the method of canal staining and root cleaning. In addition to the most prevalent types II and IV canal systems, Wasti et $\mathrm{al}^{14}$ reported that it was found type VI configuration Itwo separate root canals leave the pulp chamber, merge in the body of the root, and again divide short of apex to exit as two separate and distinct canals) in the mesiobuccal root with two canals.

In the present study, the accessibility was observed only in $19.8 \%$ of maxillary first molars in second mesiobuccal canal. This prevalence is much lower than the total number of second mesiobuccal canal orifices because if an orifice was located but size $0.6,0.8$ or $10 \mathrm{~K}$-type files was unable to penetrate into the canal, no bur was used to remove dentine on the pulp chamber floor to prevent possible perforation. In case of the penetration of size $0.6,0.8$ or $10 \mathrm{~K}$-type files into the canal it was stipulated to reach the apex for the acceptance of the root canal as accessible. These criteria are probably the reason for the lower incidence of the accessibility in second mesiobuccal canals.

The complexity of the root canal system was known such as the furcation, accessory and lateral canal, intercanal connection, apical deltas. ${ }^{?}$
Teixeira et $\mathrm{al}^{23}$ reported that the incidence of isthmus in the mesiobuccal root of the maxillary first molars was high, particularly in sections $3-5 \mathrm{~mm}$ from the apex. The findings of Jung et $\mathrm{al}^{24}$ supported this and it was found that the prevalence of anatomical variations was highest at the apical $4 \mathrm{~mm}$ level. For this reasons, it is important to reach the apical area for the successful root canal therapy. In many studies the prevalence and factors affecting the negotiability of the MB2 in maxillary molars was examined ${ }^{20,25}$ but there is little research about the location. Kulild and Peters ${ }^{3}$ and Gilles and Reader ${ }^{26}$ described the MB2 canal according to the main mesiobuccal canal and found the mean distance of the mesiolingual orifice from the mesiobuccal orifice 2.31 and $1.82 \mathrm{~mm}$, respectively. Görduysus et $\mathrm{al}^{16}$ and Zhang et $\mathrm{al}^{27}$ remarked that the location of the MB2 canal varied not only in relation to the main mesiobuccal canal. There was another reference point, the palatal canal orifice. Zhang et al ${ }^{27}$ reported that the MB2 canal was located less than $1 \mathrm{~mm}$ mesially to the MB-P line and $2 \mathrm{~mm}$ palatally from the MB orifice. Görduysus et $\mathrm{al}^{18}$ determined the location of the MB2 canal in 45 extracted maxillary molars and found these measurements $0.69 \mathrm{~mm}$ mesially and $1.65 \mathrm{~mm}$ palatally. The results of the present study about the distance between the MB2 and MB-P line are in agreement with those of Zhang et $\mathrm{al}^{27}$ but there is significant differences about the location of the MB2 canal orifice according to the main MB canal. In our study it was observed that only, in $24.4 \%$ of two-canalled mesiobuccal roots these canals originate mesial to the main MB canal, but mainly (65/86-76\%) were found distal to the main MB canal. This is important for the access cavity design. Weller and Hartwell ${ }^{28}$ suggested that if the initial access is changed from a classical triangular shape to a more rhomboidal shape, the probability of finding the MB2 canal increases.

\section{CONCLUSIONS}

According to the results of the present study, the majority of the MB2 canal orifices (76\%) originate distal to the main MB canal and most of the MB2 canal orifices are normally in our vision of the classical triangular access cavity for this reason a careful examination of the pulpal floor should be conducted. 


\section{REFERENCES}

1. Hess W, Zurcher E. The Anatomy of the Root Canals of the Teeth of the Permanent and Deciduous Dentitions. Newyork: William Wood \& Co,1925, pp.1-39.

2. Weine FS, Healey HJ, Gerstein H, Evanson L. Canal configuration in the endodontic significance. Oral Surg Oral Med Oral Pathol 1969;28:419-425.

3. Kulild JC, Peters DD. Incidence and configuration of canal systems in the mesiobuccal root of maxillary first and second molars. J Endod 1990;16:311-317.

4. Weine FS, Hayami S, Hata G, Toda T. Canal configuration of the mesiobuccal root of the maxillary first molar of a Japanese sub-population. Int Endod J 1999;32:79-87.

5. Alavi AM, Opasanon A, Ng YL, Gulabivala K. Root and canal morphology of Thai maxillary molars. Int Endod $J$ 2002;35:478-485.

6. Sempira HN, Hartwell GR. Frequency of second mesiobuccal canals in maxillary molars as determined by use of an operating microscope: a clinical study. $J$ Endod 2000;26:673-674

7. Gulabivala K, Aung TH, Alavi A, Ng YL. Root and canal morphology of Burmese mandibular molars. Int Endod $J$ 2001;34:359-370.

8. Pomeranz HH, Fishelberg G. The secondary mesiobuccal canal of the maxillary molars. JADA 1974;88:119-124.

9. Vertucci FJ. Root canal anatomy of the human permanent teeth. Oral Surg Oral Med Oral Pathol 1984;58:589-599.

10. Neaverth EJ, Kotler ML, Kaltenbach RF. Clinical investigation (in vivo) of endodontically treated maxillary first molars. J Endod 1987;13:506-512.

11. Stropko JJ. Canal morphology of maxillary molars: clinical observations of canal configurations. J Endod 1999;25:446450.

12. Fogel HM, Peikoff MA, Christie WH. Canal configuration in the mesiobuccal root of the maxillary first molar: a clinical study. J Endod 1994;20:135-137.

13. Peikoff MD, Christie WH, Fogel HM. The maxillary second molar: variations in the number of roots and canals Int Endod $J$ 1996;29:365-369.

14. Wasti F, Shearer AC, Wilson NH. Root canal systems of the mandibular and maxillary first permanent molar teeth of south Asian Pakistanis. Int Endod J 2001;34:263-266.

15. Ng YL, Aung TH, Alavi A, Gulabivala K. Root and canal morphology of Burmese maxillary molars. Int Endod $J$ 2001;34:620-630.

16. Görduysus MO, Görduysus M, Friedman S. Operating microscope improves negotiation of second mesiobuccal canals in maxillary molars. J Endod 2001;27:683-686.
17. Buhrley LJ, Barrows MJ, BeGole EA, Wenckus CS. Effect of magnification on locating the MB2 canal in maxillary molars. J Endod 2002;28:324-327.

18. Baldassari-Cruz LA, Lilly JP, Rivera EM. The influence of dental operating microscope in locating the mesiolingual canal orifice. Oral Surg Oral Med Oral Pathol Oral Radiol Endod 2002;93:190-194.

19. Yoshioka T, Kobayashi C, Suda H. High detection rate of root canal orifices under a microscope. J Endod 2002;28:452453.

20. Yoshioka T, Kikuchi I, Fukumoto Y, Kobayashi C, Suda H. Detection of the second mesiobuccal canal in mesiobuccal roots of maxillary molar teeth ex vivo. Int Endod $J$ 2005;38:124-128.

21. Coutinho Filho T, La Cerda RS, Gurgel Filho ED, de Deus GA, Magalhaes KM. The influence of the surgical operating microscope in locating the mesiolingual canal orifice: a laboratory analysis. Pesqui Odontol Bras 2006;20:59-63.

22. Omer OE, Al Shalabi RM, Jennings M, Glennon J, Claffey NM. A comparison between clearing and radiographic techniques in the study of the root-canal anatomy of maxillary first and second molars. Int Endod J 2004;37:291-296.

23. Teixeira FB, Sano CL, Gomes BPFA, Zaia AA, Ferraz CCR, Souza-Filho FJ. A preliminary in vitro study of the incidence and position of the root canal isthmus in maxillary and mandibular first molars. Int Endod J 2003;36:276-280.

24. Jung IY, Seo MA, Fouad AF, Spangberg LS, Lee SJ, Kim HJ, Kum KY. Apical anatomy in mesial and mesiobuccal roots of permanent first molars. J Endod 2005;31:364-368.

25. Ibarrola JL, Knowles KI, Ludlow MO, McKinley IB Jr. Factors affecting the negotiability of second mesiobuccal canals in maxillary molars. J Endod 1997;23:236-238.

26. Gilles J, Reader A. A SEM investigation of the mesiolingual canal in human maxillary first and second molars. Oral Surg Oral Med Oral Pathol 1990;70:638-643.

27. Zhang CF, Ding RY, Yin XZ, Zhao BH, Lin QG. Location and negotiation of second mesiobuccal canals in maxillary molars. Zhonghua Kou Qiang Yi Xue Za Zhi 2003;38:86-88.

28. Weller RN, Hartwell GR. The impact of improved access and searching techniques on detection of the mesiolingual canal in maxillary molars. J Endod 1989;15:82-83. 